\title{
Using the CT as a Guided Imaging Modality in Spinal Injections for Chronic Low Backache; Is it the Preferred Modality?
}

\author{
SAMEH A. KHODAIR, M.D.* and HOSAM ELNAGGAR, M.D.** \\ The Department of Radiology, Faculty of Medicine, Tanta University* and The Department of Rheumatology and Rehabilitation, \\ Faculty of Medicine, MUST University**, Egypt
}

\begin{abstract}
Background: Low back pain is the most common cause of disability in people under 45 years of age. In such patients, spinal injections allow a functional assessment of the anatomic structures that are suspected to be the cause of pain. To minimize the complications and maximize test of accuracy, spinal injections are best performed with imaging guidance.

Aim of Study: The aim of the study is to evaluate the role of CT guided spinal injections in management of chronic low back pain.

Methods and Material: 120 patients with chronic low back pain after failure of adequate conservative treatment for at least 6 months were enrolled in this study. We excluded patients with focal discs herniation, motor deficit, and bleeding tendency. All our study population were subjected to pain scoring by Revised Oswestry disability index before and after 1 month of injections, standard X-rays, MRI of the lumbar spine and appropriate CT guided spinal injection was done using a combined solution of anesthetic and long acting steroid.

Results: $35 \%$ of the patients had low backache with radicular pain, $65 \%$ had low back pain with no radicular pain. We performed facet joint injection in $20 \%$ of our patients, selective nerve root block in $20 \%$, sacroiliac joint injection in $27.5 \%$ of our patients and $32.5 \%$ underwent combined injections. The mean value of Revised Oswestry disability index before injections was 27.6 and 16.9 after injections of all patients group. There were overall significant improvement in pain relief as well as physical, occupational and psychological status during 6 months follow-up.

Conclusion: CT guided facet joint injection, sacroiliac joint injection, selective nerve root block could be effective modality in management of chronic low back pain and its sequels.
\end{abstract}

Key Words: CT - Low backache - Transforaminal injection.

\section{Introduction}

LOW back pain is the most common cause of disability in people under 45 years of age [1]. It

Correspondence to: Dr. Sameh A. Khodair,

E-Mail: samehkhodair@gmail.com represents a relevant social and economic burden in developed countries. The financial burden of low back pain is enormous including the costs of medical care, indemnity payment, productivity loss, employee retiring, administrative expenses and litigation [2].

In different studies, facet joints, intervertebral discs, sacroiliac joints, and spinal nerves have been identified as the most common sources of chronic low back pain. Classification of low back pain as radicular and non radicular, allows a systematic approach to reach a diagnosis and helps guide the neurosurgeon as well as interventional radiologist toward the most likely pain generator [3] .

A spinal cause was identified only in $15 \%$ of patients with chronic low back pain without a demonstrated neurologic deficits or a visible herniated disc on imaging [4]. In such patients, spinal injections allow a functional assessment of the anatomic structures that are suspected to be the cause of pain. Diagnostic spinal injections are performed to test the hypothesis that a specific spinal structure could be symptomatic. If a symptomatic structure has been identified, spinal injections may be used for pain management [5] .

To minimize the complications and maximize test of accuracy, spinal injections are best performed with imaging guidance [6,7]. Fluoroscopy and CT may be used for the whole spectrum of spinal injections [8].

\section{Patients and Methods}

This prospective study was conducted between August 2018 and August 2019 after obtaining Research Ethics Committee approval, in Depart- 
ment of Radiology and Diagnostic Imaging, Tanta University. Informed consents were obtained from all patients after explanation of the procedures, their benefits and possible risks.

The study included one hundred and twenty patients, 72 female patients and 48 male patients. Their mean age was 49 years. The inclusion criteria were patients with chronic low back pain as well as radicular pain who had received adequate conservative treatment for at least 6 months without pain relief satisfaction. They referred to Radiology and Diagnostic Department for CT guided injection. The exclusion criteria were, patients with motor neurological deficit, local or systemic infection and/or bleeding tendency.

Our study population was divided according to injection procedure into:

- Group I: Patients underwent facet joint injection.

- Group II: Patients underwent sacroiliac joint injection.

- Group III: Patients underwent nerve root injection.

- Group IV: Patients underwent more than one modality injection.

All patients included in this study were subjected to; through history taken and pain scoring by Revised Oswestry disability index. This was done by a standard questionnaire conducted directly before, after one week and after one month following the injection. Neurological examinations with special emphasis on local spinal examination. Standard X-rays of the lumbar spine in 2 planes (antro-posterior and lateral view) and MRI of the lumbar spine.

\section{Technique of CT guided injection:}

All spinal injections in our study were done under CT guidance (Siemens, Sensation multislice 16) with vital signs monitoring and complete aseptic precautions, no sedation used, no specific patient preparations needed before the maneuver. The patient was in a comfortable prone position, a mark is situated upon the mid line overlying the region of interest, CT scanning of the lumber vertebrae was taken. The section of needle insertion was marked on the patient skin by the gaudiness of the machine laser light. The angle of entrance, distance from the midline and depth from the skin to the point where the needle tip was needed to reach was measured on the workstation to ensure an accurate placement of the needle. After insertion of the $22 \mathrm{G}$ spinal needle, $2 \mathrm{ml}$ of air was injected and re-scanning the site of the needle was done to evaluate its position and distribution of the air around the region of interest. Once the position of the needle tip is confirmed, a combination consisting of $2 \mathrm{ml}$ of methyl prednisolone and $1 \mathrm{ml}$ mepivacaine $3 \%$ were injected. Care was always taken to aspirate before injection, to avoid accidental intravascular injection.

\section{Statistical analysis:}

Statistical analysis was performed with the Minitab Ver. 16 (Minitab Inc. USA). The paired $t$ test was used to analyze differences of the revised Oswestry disability index before injection, after one week and after one month following the injection. $p$-values less than or equal to 0.05 indicated a statistically significant difference.

\section{Results}

One hundred and twenty patients were enrolled in this study. Their mean age was 49 years. Seventy two $(60 \%)$ were female while forty eight (40) \% were male. All patients had pain for a period ranged from 2 to 3 years and all used analgesics for at least 12 months. $35 \%$ of the patients had low back pain with radicular pain, $65 \%$ had low back pain without radicular pain. All patients had back tenderness while only $60 \%$ had positive straight leg rising. Their Revised Oswestry Disability Index before injection ranged from 11 to 38 representing $22 \%$ to $76 \%$ expressing moderate disability to crippled.

Plain X-ray films were normal in $60 \%$ of patients, $37.5 \%$ had marginal osteosclerosis and osteophytes formation, $34.1 \%$ showed narrowing of inter-vertebral disc spaces and non of these patients showed erosion or sclerosis of sacroiliac joint. On MRI examination: $16.6 \%$ had normal MRI, while $83.3 \%$ had degenerative changes of lumbar intervertebral discs. $15.8 \%$ had facet osteoarthropathy, 55\% had diffuse posterior lumbar intervertebral disc bulge, $7.5 \%$ had annular tear and $2.5 \%$ had MRI signs of sacro-ilieitis (Table 1).

According to imaging findings and clinical evaluation; twenty four patients $(20 \%)$ underwent facet joint injection; 2 of them were injected at L3-4 level. 9 patients were injected at L4-5 level, 8 were injected at L5-S1 level and 5 patients were injected at both L4-5 and L5-S1 level. Among these patients; 9 patients needed to repeat the injection after two weeks.

Thirty three patients $(27.5 \%)$ underwent sacroiliac joint injection, only one patient needed to 
repeat sacroiliac injection. Twenty four patients $(20 \%)$ underwent transforamenal perineural injection, 14 of them were injected at L4-5 level and 6 at L5-S 1 level, two patients at L3-4 level and two at both L4-5 and L5-S 1 level. Eighteen patients of them were injected twice with two weeks interval.

Thirty nine patients $(32.5 \%)$ underwent more than one procedure ( 11 patients received simultaneous facet joint injection and transforaminal perineural injection while 28 patients received sacroiliac joint injection with facet joint injection (Table 2).

Follow-up and outcome: Table (3) illustrates Revised Oswestry Disability Index before, after 1 week, after 1 month of injection for different injection procedures. Comparison between Revised Oswestry Disability Index before and after injection was statistically significant in case of facet joint injection, nerve root block and sacroiliac joint injection while non significant in patients who received combined modalities of injections.
Table (1): The relation between radiological findinds in patients and the Revised Oswestry disability index.

\begin{tabular}{lcc}
\hline Total patients 120 & $\begin{array}{c}\text { Non radicular } \\
78 \text { patients }(65 \%)\end{array}$ & $\begin{array}{l}\text { Radicular 42 } \\
\text { patient (35\%) }\end{array}$ \\
\hline RODI & $11-33$ & $12-38$ \\
& Mean & Mean \\
& $23.11 \pm 4.30$ & $26.85 \pm 6.20$ \\
X-ray: & & \\
Normal & 57 & 15 \\
Disc space narrowing & 9 & 32 \\
Osteophytes & 20 & 25 \\
Sacro-ilieitis & 0 & 0 \\
MRI findings: & & \\
Normal & 20 & 0 \\
Disc degeneration & 58 & 42 \\
Annular tear & 7 & 2 \\
Disc Bulge & 33 & 33 \\
Facet arthropathy & 15 & 4 \\
Sacro-ilieitis & 3 & 0 \\
\hline
\end{tabular}

Table (2): Different procedure, number and level of injections of the patients.

\begin{tabular}{|c|c|c|c|c|c|c|c|c|c|}
\hline \multirow{2}{*}{ Injection modality } & \multirow{2}{*}{$\begin{array}{l}\text { Number } \\
\text { of cases }\end{array}$} & \multirow{2}{*}{ Percent } & \multirow{2}{*}{ Side of injection } & \multicolumn{4}{|c|}{ Level of injection } & \multicolumn{2}{|c|}{$\begin{array}{l}\text { Frequency } \\
\text { of injection }\end{array}$} \\
\hline & & & & L3-4 & L4-5 & L5-S 1 & $\begin{array}{l}\text { L4-5 \& } \\
\text { L5-S } 1\end{array}$ & $\begin{array}{l}\text { Single } \\
\text { injection }\end{array}$ & $\begin{array}{l}\text { Multiple } \\
\text { injection }\end{array}$ \\
\hline Facet joint injection & 24 & $20 \%$ & 18 unilateral- 6 bilateral & 2 & 9 & 8 & 9 & 15 & 9 \\
\hline Sacroiliac Joint injection & 33 & $27.5 \%$ & 8 unilateral- 25 bilateral & - & - & - & - & 32 & 1 \\
\hline Nerve root block & 24 & $20 \%$ & All unilateral & 2 & 14 & 6 & 2 & 6 & 18 \\
\hline Combined injection & 39 & $32.5 \%$ & $\begin{array}{l}11 \text { with TF \& FJ- } \\
28 \text { SI \& FJ }\end{array}$ & $\begin{array}{l}1 \\
\text { with SI }\end{array}$ & $\begin{array}{l}6 \text { with } \\
\text { SI \& FJ }\end{array}$ & $\begin{array}{l}3 \text { with } \\
\text { SI \& F. }\end{array}$ & $\begin{array}{l}1 \\
\text { with FJ }\end{array}$ & 12 & 27 \\
\hline
\end{tabular}

Table (3): Comparison of Revised Oswestry disability index before, after 1 week, after 1 month of injection for different injection modalities.

\begin{tabular}{llllll}
\hline \multirow{2}{*}{ Injection modality } & Time & $\begin{array}{c}\text { Range } \\
\text { of R.O.I }\end{array}$ & Mean \pm SD & \multicolumn{2}{c}{ Paired $t$-test } \\
\cline { 4 - 6 } & & & $t$ & $p$-value \\
\hline Facet joint injection & Before injection & $20-30$ & $26.63 \pm 4.00$ & & \\
& 1 week after injection & $7-20$ & $15.00 \pm 3.78$ & 6.755 & $0.001 *$ \\
& 1 month after injection & $7-18$ & $14.50 \pm 3.25$ & 7.024 & $0.001 *$ \\
& Before injection & $20-37$ & $26.29 \pm 5.53$ & & \\
Nerve root block & 1 week after injection & $8-37$ & $18.14 \pm 9.30$ & 4.061 & $0.007 *$ \\
& 1 month after injection & $8-37$ & $18.14 \pm 9.30$ & 4.061 & $0.007 *$ \\
Sacroiliac joint injection & Before injection & $28-29$ & $28.50 \pm 0.71$ & & \\
& 1 week after injection & $12-15$ & $13.50 \pm 2.12$ & 15.000 & $0.042^{*}$ \\
& 1 month after injection & $12-15$ & $11.50 \pm 2.12$ & 15.000 & $0.042^{*}$ \\
Combined modality injection & Before injection & $11-38$ & $27.67 \pm 14.57$ & & \\
& 1 week after injection & $5-29$ & $19.67 \pm 12.86$ & 3.179 & 0.086 \\
& 1 month after injection & $5-29$ & $19.67 \pm 12.86$ & 3.179 & 0.086 \\
\hline
\end{tabular}




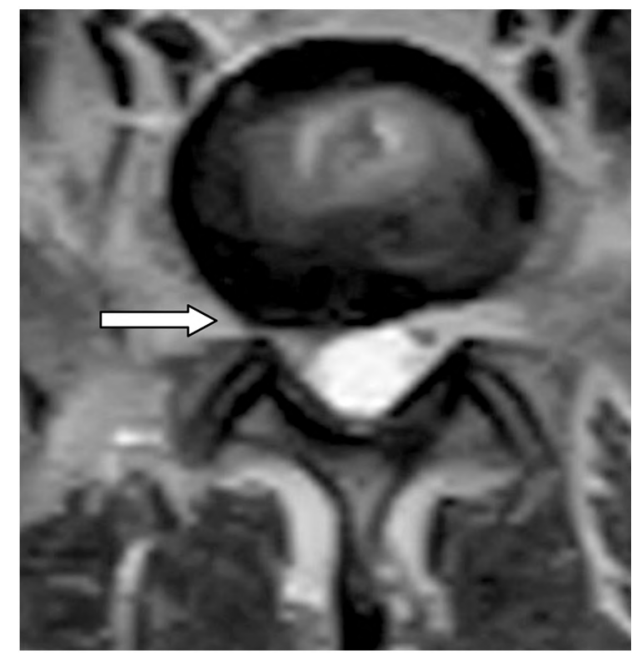

Fig. (1): A male patient aged 42 years old, with lower back pain and right side radicular pain one year ago. Axial T2 WI L4-5 disc showed diffuse disc bulge that encroaches more upon the right exit neural foramen.

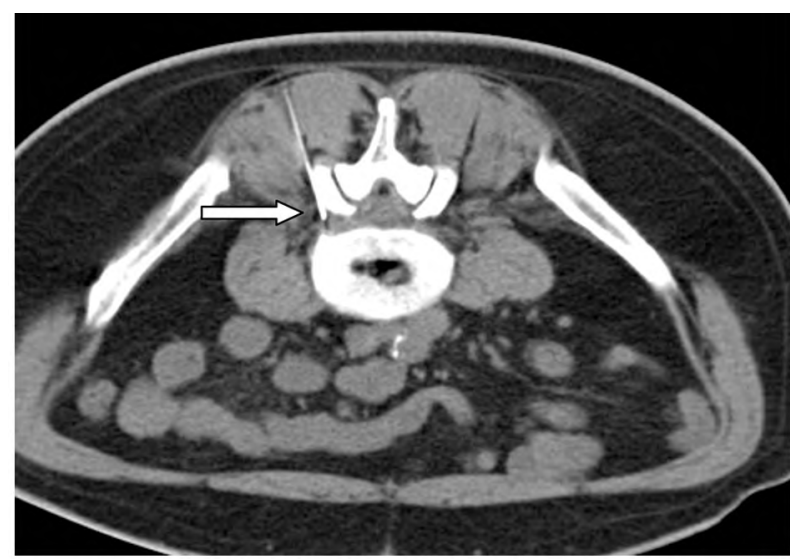

Fig. (2): Insertion of the spinal needle in a perineural situation after estimation of the appropriate angle on insertion as well as the depth of insertion from the skin surface.

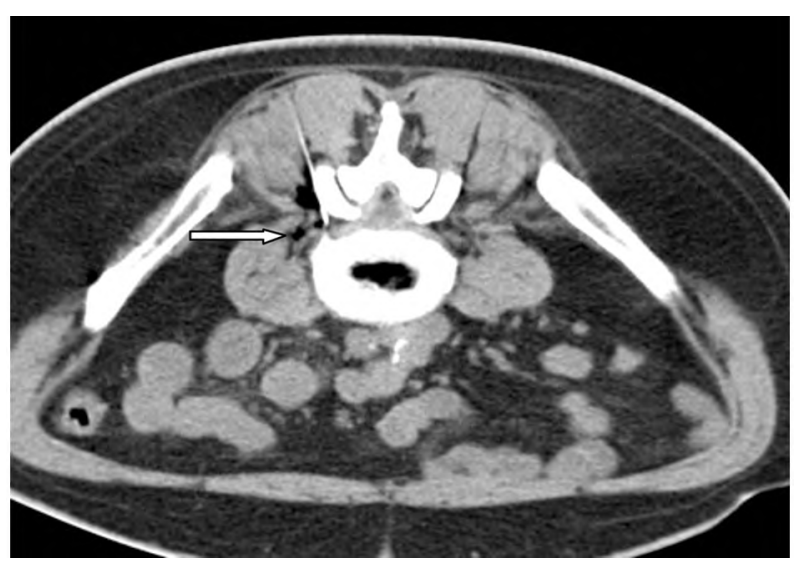

Fig. (3): Injection of $2 \mathrm{ml}$ of air with distribution of the air along the course of the exit nerve root which confirm the proper situation of the needle tip just before injection.

\section{Discussion}

Low back pain is one of the most frequently reported devastating symptoms in the industrialized world [9]. About two-thirds of the population suffers from back pain at some point of time during their life span [10] and this symptom incapacitates $20 \%$ of them for long periods ( $>4$ weeks) [11]

In this work, patients with radicular pain either with or without intervertebral disc bulge on MRI imaging had received nerve root block at the level of intervertebral disc bulge or according to the site of pain guided by body map dermatomal distribution. Zennaro et al., [12], reported that selective nerve root injection resulted in pain relief in $70 \%$ of patients of study and in $95 \%$ of patients with foraminal stenosis secondary to degenerative stenosis rather than herniated disc.

Patients had tenderness over sacroiliac joint with erosion and sclerosis of joint underwent sacroiliac joint injection. Luukkainen et al., [13] used criteria for sacroiliac joint injection comprised of the region of the pain, tenderness in the SIJ, and positive results on at least one of three provocation tests: Gaenslen's test, Patrick's test, or Newton's test.

In this study, levels for injection were selected on the basis of maximal local tender point, and imaging evidence of the pathology. It is often difficult to localize the pain to one level, so that generally two and occasionally three levels were injected. If the pain is bilateral, injections were performed bilaterally.

In the present study, we used the Revised Oswestry Disability Index as a scale for assessment of pain severity and functional status of our patients. It was done by a standard questionnaire before, after 1 week and after 1 month of spinal injections. Schulte et al., [14] conducted a prospective study included 39 patients with chronic low back pain diagnosed as facet joint arthropathy syndrome. Injection of steroid, lidocaine, and 5\% phenol under fluoroscopic control. Outcomes were determined on a follow-up based specialty questionnaire including: Visual analog scale, McNab criteria, and pain disability index. Pain relief of up to 6 months was reported after the treatment. The outcome was assessed as excellent or good by $62 \%$ of the patients 1 month following the procedure, by 41 after 3 months, and 36 after 6 months.

In Conclusion; the variety of studies techniques with satisfactory outcome and positive impact on social and psychological status of patients could 
make guided spinal injection recommended option for management of chronic low back pain.

\section{References}

1- LUO X., PIETROBON R., SUN S.X., et al.: Estimates and patterns of direct health care expenditures among individuals with back pain in the United States. Spine, 29: 79-86, 2004.

2- STEENSTRA I.A., VERBEEK J.H., HEYMANS M.W., et al.: Prognostic factors for duration of sick leave in patients sick listed with acute low back pain: A systematic reviewof the literature. Occupational and Environmental Medicine, Dec., 62 (12): 851-60, 2005.

3- BOGDUK N.: Clinical anatomy of the lumbar spine and sacrum. 4th ed. Edinburgh, Scotland: Elsevier/Churchill Livingstone, 2005.

4- WEISHAUPT D., ZANETTI M., HODLER J., et al. Painful lumbar disk derangement: Relevance of endplate abnormalities at MR imaging. Radiology, 218: 420-7, 2001.

5- JARVIK J.G. and DEYO R.A.: Diagnostic evaluation of low back pain with emphasis on imaging. Ann. Intern. Med., 137: 586-97, 2002.

6- GILULA L.A. and LANDER P.: Management of spinal pain with imaging-guided injection. RadioGraphics, 23: 189-90, 2003

7- GANGI A., DIETEMANN J.L. and MORTAZAVI R. CT-guided interventional procedures for pain management in the lumbosacral spine. RadioGraphics, 18: 621-33, 1998.

8- SILBERGLEIT R., MEHTA B.A. and SANDERS W.P.: Imaging-guided injection techniques with fluoroscopy and CT for spinal pain management. Radio-Graphics, 21: 927-39, 2001

9- LUO X., PIETROBON R., SUN S.X., et al.: Estimates and patterns of direct health care expenditures among individuals with back pain in the United States. Spine, 29: 79-8, 2004.

10- FRYMOYER J.W.: Back pain and sciatica. N. Engl. J. Med., 318: 291-300.3, 1988

11- HALDEMAN S.: Failure of pathology to predict back pain. Spine, 15: 718-24, 1990.

12- ZENNARO H., DOUSSET V., VIAUD B., et al.: Periganglionic foraminal steroid injections performed under CT control. AJNR Am. J. Neuroradiol., 19: 349-52, 1998.

13- LUUKKAINEN R.K., WENNERSTRAND P.V., KAUTIAINEN H.H., et al.: Efficacy of periarticular corticosteroid treatment of the sacroiliac joint in nonspondylarthropathic patients with chronic low back pain in the region of the sacroiliac joint. Clin. Exp. Rheumatol., 20: 52-4, 2002.

14- SCHULTE T.L., PIETILA T.A., HEIDENREICH J., et al.: Injection therapy of lumbar facet syndrome: A prospective study. Acta Neurochir. (Wien), 148: 1165-72, 2006.

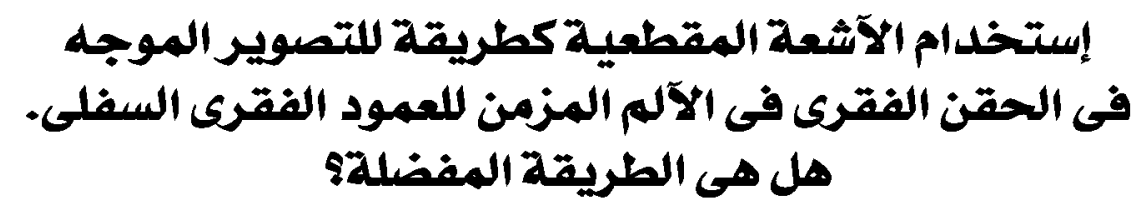

الفرض من هذا البحث هو تقييم لوق حقن العمود الفقرى الموجهة بالآثعة المقطعية لعلاج آلام آسفل الظهر المزمنة. وشملت الطرق والمواد

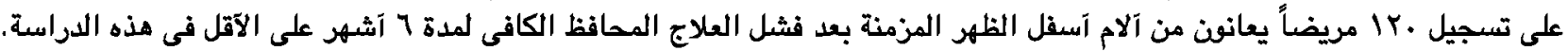

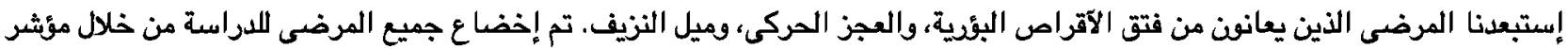

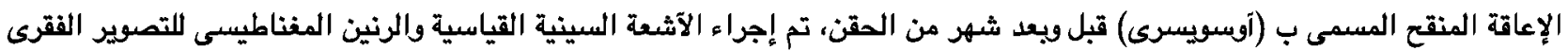

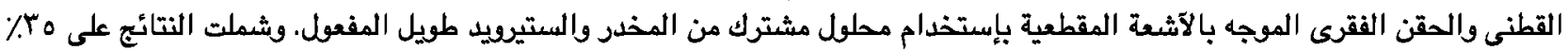

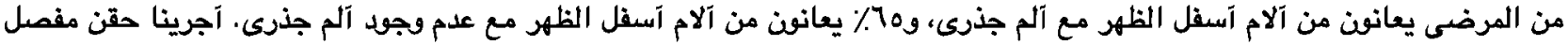

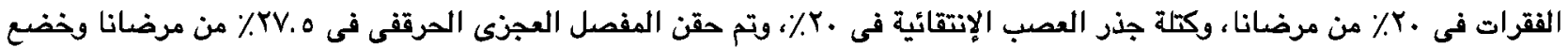

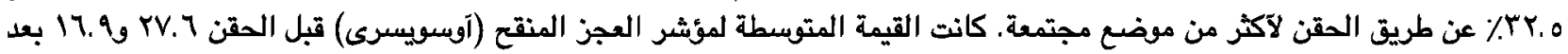

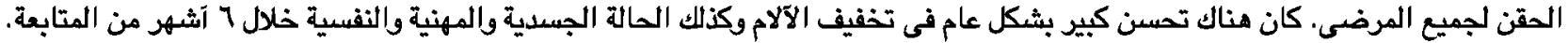
والخلاصة آنه يمكن آنت يكنف حقن مفصل الفقرات، وحقن المفصل العجزى الصرقفى، وآيضاً كتلة جذر العصب الإنتقائية بالآثعة المقطعية الموجهة طريقة فعالة في علاج آلام آسفل الظهر المزمنة وتوابعها. 